\title{
Article \\ A Genome-Wide Association Study on Liver Stiffness Changes during Hepatitis C Virus Infection Cure
}

\author{
Anaïs Corma-Gómez ${ }^{1,+}$, Juan Macías ${ }^{1,2,+} \mathbb{D}^{\mathbb{D}}$, Antonio Rivero ${ }^{3}$, Antonio Rivero-Juarez ${ }^{3}$, Ignacio de los Santos 4 (D), \\ Sergio Reus-Bañuls ${ }^{5}$ (D), Luis Morano ${ }^{6} \mathbb{D}$, Dolores Merino ${ }^{7}$, Rosario Palacios ${ }^{8}$, Carlos Galera ${ }^{9}$, \\ Marta Fernández-Fuertes ${ }^{1}$, Alejandro González-Serna ${ }^{1}$, Itziar de Rojas ${ }^{10,11}$, Agustín Ruiz ${ }^{10,11}$, María E. Sáez ${ }^{12} \mathbb{D}_{\text {, }}$ \\ Luis M. Real ${ }^{1,13, *(\mathbb{D})}$ and Juan A. Pineda ${ }^{1,2}$
}

Citation: Corma-Gómez, A.; Macías, J.; Rivero, A.; Rivero-Juarez, A.; de los Santos, I.; Reus-Bañuls, S.; Morano, L.; Merino, D.; Palacios, R.; Galera, C.; et al. A Genome-Wide Association Study on Liver Stiffness Changes during Hepatitis C Virus Infection Cure. Diagnostics 2021, 11, 1501. https://doi.org/10.3390/ diagnostics11081501

Academic Editor: Jean-Francois H. Geschwind

Received: 14 July 2021

Accepted: 16 August 2021

Published: 20 August 2021

Publisher's Note: MDPI stays neutral with regard to jurisdictional claims in published maps and institutional affiliations.

Copyright: (c) 2021 by the authors. Licensee MDPI, Basel, Switzerland. This article is an open access article distributed under the terms and conditions of the Creative Commons Attribution (CC BY) license (https:// creativecommons.org/licenses/by/ $4.0 /)$.
1 Unidad Clínica de Enfermedades Infecciosas y Microbiología, Hospital de Valme, 41014 Sevilla, Spain; anais.corgo@gmail.com (A.C.-G.); juan.macias.sanchez@gmail.com (J.M.); martaffuertes@gmail.com (M.F.-F.); alextantalo@gmail.com (A.G.-S.); japineda@telefonica.net (J.A.P.)

2 Departamento de Medicina, Universidad de Sevilla, 41009 Sevilla, Spain

3 Unidad de Enfermedades Infecciosas, Hospital Universitario Reina Sofía, Instituto Maimonides de Investigación Biomédica de Córdoba (IMIBIC), Universidad de Córdoba, 14004 Córdoba, Spain; ariveror@gmail.com (A.R.); arjvet@gmail.com (A.R.-J.)

4 Unidad de Medicina Interna y Enfermedades Infecciosas, Hospital de La Princesa, 28006 Madrid, Spain; isantosg@hotmail.com

5 Unidad de Enfermedades Infecciosas, Hospital General Universitario de Alicante, 03010 Alicante, Spain; reus_ser@gva.es

6 Unidad de Patología Infecciosa, Hospital Universitario Alvaro Cunqueiro, Instituto de Investigación Sanitaria Galicia Sur (IISGS), 36312 Vigo, Spain; luis.morano.amado@gmail.com

7 Unidad de Enfermedades Infecciosas, Hospital Universitario Juan Ramón Jiménez, 21005 Huelva, Spain; merinolola080@gmail.com

8 Unidad de Enfermedades Infecciosas y Microbiología, Hospital Virgen de la Victoria, 29010 Málaga, Spain; rosariopalaci@gmail.com

9 Unidad de Medicina Interna, Hospital Clínico Universitario Virgen de la Arrixaca, 30120 Murcia, Spain; carlosgalerap@gmail.com

10 Fundació ACE-Institut Català de Neurociències Aplicades, Universitat Internacional de Catalunya (UIC), 08028 Barcelona, Spain; iderojas@fundacioace.org (I.d.R.); aruiz@fundacioace.com (A.R.)

11 CIBERNED Centro de Investigación Biomédica en Red de Enfermedades Neurodegenerativas, Instituto de Salud Carlos III, 28029 Madrid, Spain

12 Centro Andaluz de Estudios Bioinformáticos (CAEBI, SL), 41013 Sevilla, Spain; mesaez@caebi.es

13 Departamento de Especialidades Quirúrgicas, Bioquímica e Inmunología, Universidad de Málaga, 29010 Málaga, Spain

* Correspondence: lmreal67b@gmail.com; Tel.: +34-95-501-5799

+ These authors contributed equally to this work.

Abstract: Liver stiffness (LS) at sustained virological response (SVR) after direct-acting antivirals (DAA)-based therapy is a predictor of liver events in hepatitis $\mathrm{C}$ virus (HCV)-infected patients. The study aim was to identify genetic factors associated with LS changes from the moment of starting anti-HCV therapy to SVR. This prospective study included HCV-infected patients from the GEHEP011 cohort who achieved SVR with DAA-based therapy, with LS pre-treatment $\geq 9.5 \mathrm{kPa}$ and LS measurement available at SVR. Plink and Magma software were used to carry out genome-wide single-nucleotide polymorphism (SNP)-based and gene-based association analyses, respectively. The ShinyGO application was used for exploring enrichment in Gene Ontology (GO) categories for biological processes. Overall, 242 patients were included. Median (quartile 1, quartile 3) LS values at pre-treatment and at SVR were $16.8(12,28) \mathrm{kPa}$ and $12.0(8.5,19.3) \mathrm{kPa}$, respectively. Thirty-five SNPs and three genes reached suggestive association with LS changes from the moment of starting antiHCV therapy to SVR. GO categories related to DNA packaging complex, DNA conformation change, chromosome organization and chromatin organization were significantly enriched. Our study reports possible genetic factors associated with LS changes during HCV-infection cure. In addition, our results suggest that processes related to DNA conformation are also involved in these changes. 
Keywords: GWAS; hepatitis C virus infection; polymorphisms; sustained virological response; direct-acting antivirals; liver stiffness

\section{Introduction}

The achievement of sustained virological response (SVR) among hepatitis $C$ virus (HCV)-infected individuals is associated with a reduction in the incidence of liver complications, including hepatocellular carcinoma (HCC), as well as in all-cause mortality [1-4]. However, the risk of developing liver events does not disappear after SVR, especially among pre-treatment cirrhotic patients $[3,5,6]$. For that reason, patients with cirrhosis must undergo life-long surveillance for liver complications [7], and some authors extend this recommendation to individuals with pre-treatment advanced fibrosis [8].

Liver stiffness (LS), measured by vibration-controlled transient elastography (VCTE), is a surrogate marker of liver disease and strongly correlates with the emergence of liverrelated events among both HCV-mono-infected and HIV/HCV-coinfected subjects [9-11]. Interestingly, SVR achievement also leads to a reduction of LS in this subset. Besides, this improvement is more pronounced in patients with higher pre-treatment LS values [12,13]. Recently, it has been reported that the LS value at SVR is also a strong predictor of liver disease outcome in HCV-infected patients with pre-treatment advanced fibrosis, irrespective of HIV-coinfection [14,15].

LS reduction from the moment of therapy starting to SVR, as other complex conditions, could be partially determined by genetic factors. However, to our knowledge, no genetic association study has been conducted on this trait yet. The identification of these host factors could be helpful to understand the molecular basis of this complex trait. Moreover, it could be useful to identify individuals with lower risk of hepatic events' emergence after SVR, for whom surveillance programs for liver complications would no longer be cost-effective. In addition, these factors could be potential therapeutic targets among patients with a higher risk of clinical events after SVR. Due to this, the objective of this study was to identify genetic factors, by means of the genome-wide association study (GWAS) and gene-based association approach, related to LS changes from the moment of starting anti-HCV therapy to SVR among HCV-infected patients with pre-treatment advanced liver fibrosis.

\section{Materials and Methods}

\subsection{Design and Study Population}

In this multicenter prospective cohort study, HCV-infected patients from the GEHEP011 cohort were included (clinicaltrials.gov ID: NCT04460157). In this cohort, HCV-infected individuals, HIV-coinfected or not, who had received direct-acting antivirals (DAA)-based therapy after October 2011 at units of infectious diseases of 18 hospitals throughout Spain, are enrolled. Enrolment criteria in the cohort were: (1) have achieved SVR with DAA-based therapy, (2) have LS pre-treatment $\geq 9.5 \mathrm{kPa}$ and (3) have a LS measurement at the SVR time point.

Patients were included in this study if: (1) they had an available frozen blood sample before December 2017, (2) they were Caucasian and (3) they were non-familiarly related.

\subsection{Endpoint and Other Definitions}

The primary endpoint was the percentage of LS change from the date of starting the DAA-based regimen to the SVR time point.

LS was assessed by VCTE using a FibroScan ${ }^{\circledR}$ (Echosens, Paris, France), according to a standardized procedure [16], within the 30 days before HCV therapy initiation (baseline) and at the SVR time point. These examinations were undertaken by an experienced operator at each participating center.

SVR was defined as undetectable HCV RNA 12 weeks after the end of anti-HCV therapy. 


\subsection{Genome-Wide Genotyping and Quality Controls}

DNA isolation, genotyping methods, genotyping and samples' quality controls, principal component (PC) analyses and SNPs imputation were performed as previously described elsewhere [17]. Briefly, the Axiom 815K Biobank array (Thermo Fisher, Waltham, Massachusetts, USA) and GeneTitan Multi-Channel instrument (Thermo Fisher) were used for sample genotyping. Samples with a call rate lower that $97 \%$ were excluded. SNPs with a call rate $<95 \%$ or with a minor allele frequency (MAF) below 0.01 were removed. In addition, those individuals with heterozygosity rates greater than 0.35 , or those who were related to other individuals in the sample (Identity by state (IBS) > 0.1875), were excluded. All these analyses were carried out using Plink software (version 1.9) (https:/ / www.cog-genomics.org/plink (accessed on 1 January 2021)). PC analysis was run together with other genotype data of other populations obtained from phase 3 of the 1000 Genomes Project (http:/ / www.internationalgenome.org/ (accessed on 1 January 2021)). Only individuals of Caucasian origin (using a threshold of 6 standard deviations from mean Caucasian PC values) were kept for further analyses.

\subsection{Genome-Wide Association Analysis}

Plink software was used to perform the GWAS, under the additive model, adjusted by the four main principal components, age (continuous), sex, liver stiffness at baseline, HIV infection and treatment regimen containing interferon. Significant $p$-value was established at $5 \times 10^{-8}$ [18], whereas a $p$-value $<10^{-5}$ was considered as suggestive of statistical significance. The qqman R package (version 0.1.8) (https://CRAN.R-project.org/package= qqman (accessed on 1 January 2021)) was used for graphical representation of the GWAS single-locus analysis results (Manhattan plot). Genetic variants were annotated using the Variant Effect Predictor tool (version 104) [19]. The genomic inflation factor $(\lambda)$ was also determined by Plink.

\subsection{Gene-Based Association Study and Enrichment Analyses}

The Magma software (version 1.08) was used for calculating gene-wise statistics. This software detects multi-marker effects taking into account the physical distance and linkage disequilibrium between SNPs [20]. These analyses used a $50 \mathrm{~kb}$ upstream and downstream window around each gene to capture potential regulatory variants of these genes. The p_SNPwise_mean value calculated by the software was used for gene-based association analyses. This $p$-value was corrected by the number of genes analyzed by the software. Finally, $2 \times 10^{-6}$ was the $p$-value threshold established for this study, whereas a $p<10^{-4}$ was considered as suggestive of statistical significance.

The ShinyGO application (version 0.61) [21] (http:/ / bioinformatics.sdstate.edu/go/ (accessed on 1 January 2021)) was used for exploring enrichment in Gene Ontology (GO) categories [22,23] for biological processes using the 150 top genes obtained from the genebased association analyses. Multiple testing correction was applied using the BenjaminiHochberg method implemented in the application. We considered significant those processes with false discovery rate (FDR) $p$-value $<0.05$. Only categories with a minimum of ten overlapping genes were selected.

\subsection{Additional Statistical Analyses}

Continuous variables were expressed as median (quartile 1, quartile 3) and categorical variables as frequencies (percentage). Comparisons of categorical variables were carried out using the Pearson chi-square test or the Fisher test. Quantitative variables were compared by means of Student's $t$-test (data normally distributed) or Mann-Whitney U test (data not normally distributed). The Wilcoxon test was used to compare LS values at the baseline time point and at SVR. All these calculations were carried out using the SPSS software 25.0 (IBM Corporation, Somers, NY, USA). 


\section{Results}

\subsection{Study Population}

Among the 1035 individuals that constitute the GEHEP-011 cohort, a total of 261 (25.2\%) subjects had samples available for this study. Among them, 10 (3.8\%) individuals did not reach the DNA quality criteria to be massively genotyped, $4(1.5 \%)$ showed relatedness with other included individuals and $5(1.9 \%)$ did not have a Caucasian origin. Consequently, 242 (92.7\%) subjects constituted the study population (GWAS population).

The main characteristics of these individuals are depicted in Table 1.

Table 1. Main characteristics of both the study populations and the entire GEHEP-011 cohort.

\begin{tabular}{cccc}
\hline Variables & $\begin{array}{c}\text { GWAS Population } \\
(\boldsymbol{n}=\mathbf{2 4 2})\end{array}$ & $\begin{array}{c}\text { Gehep-011 Entire } \\
\text { Cohort }(\boldsymbol{n}=\mathbf{1 0 3 5 )}\end{array}$ & $p$ \\
\hline Age, years ${ }^{+}$ & $50(46-53)$ & $51(47-55)$ & 0.019 \\
Males, $n(\%)$ & $202(83.5)$ & $844(81.5)$ & 0.484 \\
HIV infection, $n(\%)$ & $174(71.9)$ & $667(64.4)$ & 0.028 \\
PWID, $n(\%)$ & $181(74.8)$ & $697(67.3)$ & 0.025 \\
HCV genotype 3, $n(\%)$ & $41(16.9)$ & $178(17.2)$ & 0.919 \\
HCV viral load ${ }^{\dagger \neq}$ & $163(68-398)$ & $177(59-415)$ & 0.854 \\
IFN-free treatment, $n(\%)$ & $208(86)$ & $973(94)$ & $<0.001$ \\
Baseline liver stiffness $(\mathrm{KPa})^{+}$ & $116.8(11.8-27.7)$ & $16.8(11.8-26.7)$ & 0.487 \\
\hline
\end{tabular}

PWID, People who injected drugs; HCV, Hepatitis $\mathrm{C}$ virus; IFN, interferon; $\mathrm{kPa}$, Kilo Pascals. ${ }^{\dagger}$ Median (quartile 1-quartile 3). $\ddagger$ Expressed as 100,000 UI/mL.

Direct-acting antiviral regimens used in the GWAS population for achieving sustained viral response are depicted in Supplementary Table S1.

\subsection{Changes in Liver Stiffness from Baseline to SVR}

The median (quartile 1, quartile 3) value of LS at the baseline time point was 17 (12, 28) $\mathrm{kPa}$, whereas the value at SVR was $12(8.5,19.3) \mathrm{kPa}(p<0.001)$. Overall, the median of the percentage of LS reduction from baseline to SVR was $28.8 \%(11.1 \%, 46.8 \%)$. More specifically, $27(11.1 \%)$ individuals showed a LS increment of $17.8 \%(8.5 \%, 22.3 \%)$ at SVR, whereas $212(87.6 \%)$ individuals experienced a LS reduction of $33.7 \%(16.2 \%, 48.4 \%)$. Three $(1.2 \%)$ patients did not show a LS change from baseline to SVR.

\subsection{Genome-Wide Association Study}

Initially, 592,389 SNPs passed the genotyping quality controls. After imputation, a total of 6,939,676 variants were available for subsequent analysis. The GWAS population did not reveal an admixture in the principal component analysis (Supplementary Figure S1). In addition, no overall inflation of the test statistic was observed $(\lambda=1.00)$ (Supplementary Figure S2), supporting that systematic confounding factors were unlikely.

There was not any SNP associated with the percentage of LS change from baseline to SVR at the $p$-value threshold established for GWAS (Figure 1). Nevertheless, 35 SNPs reached suggestive association with this endpoint (Table 2).

\subsection{Gene-Based Association and Enrichment Analyses}

The Magma software was used to carry out a gene-based association analysis. A total of 18,127 genes were ranked. None of them reached the multiple testing corrected $p$-value. Nevertheless, 3 genes reached suggestive statistical significance: LYPLAL1, PTGR1 and SLC8A3 (Supplementary Table S2). 


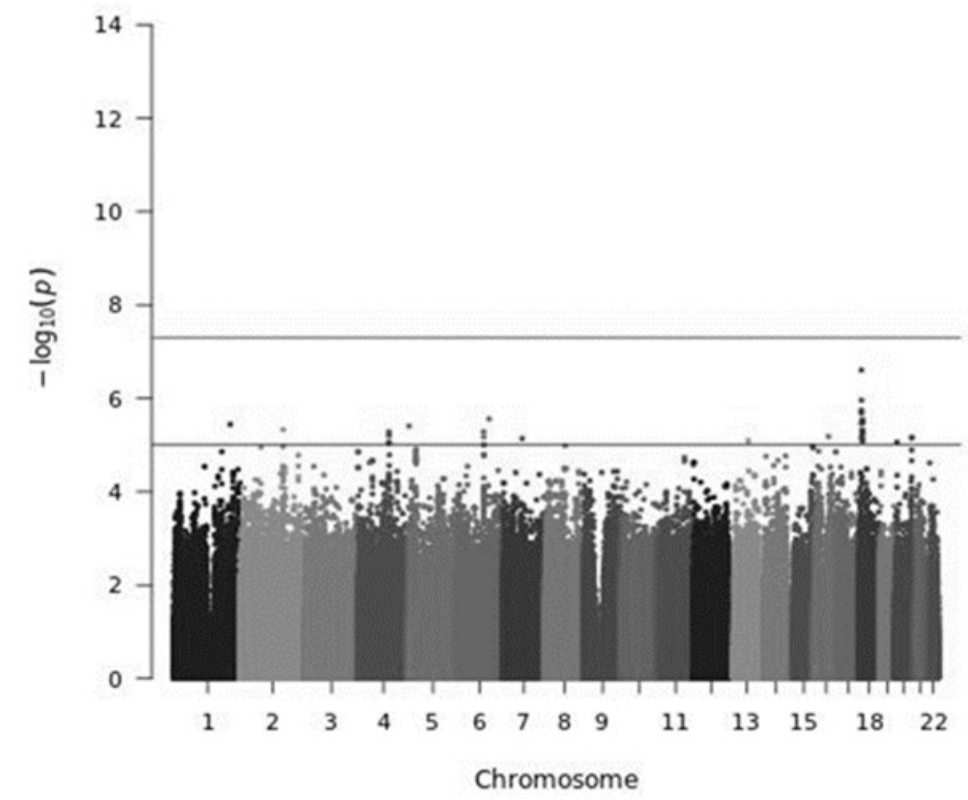

Figure 1. Manhattan plot of the GWAS on the percentage of LS changes at SVR. Horizontal lines correspond to of $1 \times 10^{-5}$ and $5 \times 10^{-8} p$-values, respectively.

Table 2. Best single-locus genetic association analysis results $\left(p<10^{-5}\right)$ obtained by plink.

\begin{tabular}{|c|c|c|c|c|c|c|c|}
\hline CHR & SNP & BP & A1 & MAF & BETA $(95 \% \mathrm{CI})$ & $p$ & Gene \\
\hline 18 & rs12606769 & 9012996 & $\mathrm{C}$ & 0.207 & $-13.27(-18.16--8.386)$ & $2.48 \times 10^{-7}$ & NDUFV2 ${ }^{+}$ \\
\hline 18 & rs9959475 & 9009311 & $\mathrm{~A}$ & 0.234 & $-12.14(-16.89--7.387)$ & $1.10 \times 10^{-6}$ & NDUFV2 ${ }^{+}$ \\
\hline 18 & rs1553736 & 9012842 & $\mathrm{C}$ & 0.215 & $-12.21(-17.09--7.333)$ & $1.80 \times 10^{-6}$ & NDUFV2 ${ }^{+}$ \\
\hline 18 & rs56232039 & 9013366 & $\mathrm{~A}$ & 0.212 & $-12.23(-17.14--7.315)$ & $2.05 \times 10^{-6}$ & NDUFV2 ${ }^{+}$ \\
\hline 6 & rs2649545 & 119771886 & A & 0.447 & $-10.98(-15.45--6.508)$ & $2.77 \times 10^{-6}$ & $M A N 1 A 1^{+}$ \\
\hline 18 & rs67749125 & 11936826 & $\mathrm{~T}$ & 0.048 & $-25.16(-35.44--14.89)$ & $2.91 \times 10^{-6}$ & $M P P E 1^{\dagger}$ \\
\hline 18 & rs8095587 & 11936664 & A & 0.048 & $-25.16(-35.44--14.89)$ & $2.91 \times 10^{-6}$ & $M P P E 1^{\dagger}$ \\
\hline 18 & rs12326768 & 11925795 & G & 0.052 & $-24.06(-33.96--14.17)$ & $3.37 \times 10^{-6}$ & MPPE1 ${ }^{\dagger}$ \\
\hline 18 & rs72942777 & 9004175 & $\mathrm{~T}$ & 0.268 & $-10.78(-15.22--6.344)$ & $3.45 \times 10^{-6}$ & NDUFV2 ${ }^{+}$ \\
\hline 1 & rs188739258 & 208743339 & $\mathrm{~T}$ & 0.013 & $-42.14(-59.53--24.75)$ & $3.60 \times 10^{-6}$ & \\
\hline 5 & rs62330020 & 311880 & $\mathrm{~T}$ & 0.047 & $-22.65(-32.03--13.26)$ & $3.94 \times 10^{-6}$ & $A H R R$ \\
\hline 2 & rs6437198 & 159613196 & $\mathrm{C}$ & 0.277 & $-11.38(-16.13--6.625)$ & $4.70 \times 10^{-6}$ & $A P L 1^{\dagger}$ \\
\hline 18 & rs12955366 & 11922625 & $\mathrm{C}$ & 0.056 & $-23.79(-33.75--13.83)$ & $4.90 \times 10^{-6}$ & $M P P E 1^{\dagger}$ \\
\hline 18 & rs9951113 & 11927429 & $\mathrm{C}$ & 0.050 & $-24.12(-34.22--14.01)$ & $4.95 \times 10^{-6}$ & $M P P E 1^{\dagger}$ \\
\hline 6 & rs9402699 & 99800122 & A & 0.277 & $-11.49(-16.31--6.662)$ & $5.19 \times 10^{-6}$ & $F A X C^{\dagger}$ \\
\hline 4 & rs8180156 & 115907555 & $\mathrm{C}$ & 0.110 & $16.62(9.637-23.6)$ & $5.22 \times 10^{-6}$ & NDST4 \\
\hline 18 & rs9962961 & 11936268 & $\mathrm{C}$ & 0.050 & $-24.11(-34.24--13.98)$ & $5.25 \times 10^{-6}$ & $M P P E 1^{\dagger}$ \\
\hline 18 & rs112570549 & 11920486 & $\mathrm{~T}$ & 0.051 & $-23.43(-33.33--13.53)$ & $5.95 \times 10^{-6}$ & $M P P E 1^{\dagger}$ \\
\hline 4 & rs17623036 & 115902626 & $\mathrm{C}$ & 0.108 & $16.61(9.57-23.66)$ & $6.32 \times 10^{-6}$ & $\mathrm{NDST}_{4}^{\dagger}$ \\
\hline 16 & rs74918996 & 53055101 & $\mathrm{C}$ & 0.022 & $-33.49(-47.71--19.27)$ & $6.55 \times 10^{-6}$ & $\mathrm{CHD9}^{+}$ \\
\hline 6 & rs6924993 & 99798835 & G & 0.281 & $-11.37(-16.21--6.538)$ & $6.69 \times 10^{-6}$ & $\mathrm{COQ}^{+}$ \\
\hline
\end{tabular}


Table 2. Cont.

\begin{tabular}{|c|c|c|c|c|c|c|c|}
\hline CHR & SNP & BP & A1 & MAF & BETA $(95 \% \mathrm{CI})$ & $p$ & Gene \\
\hline 20 & rs6122460 & 62100105 & A & 0.096 & $-15.91(-22.68--9.141)$ & $6.83 \times 10^{-6}$ & $E E F 1 A 2^{\dagger}$ \\
\hline 18 & rs11081454 & 9005806 & A & 0.257 & $-10.86(-15.49--6.238)$ & $6.96 \times 10^{-6}$ & NDUFV2 ${ }^{\dagger}$ \\
\hline 20 & rs310602 & 62109170 & $\mathrm{~A}$ & 0.101 & $-15.78(-22.51--9.059)$ & $7.07 \times 10^{-6}$ & $E E F 1 A 2^{\dagger}$ \\
\hline 7 & rs71537604 & 73067749 & $\mathrm{~T}$ & 0.071 & $-18.85(-26.9--10.81)$ & $7.30 \times 10^{-6}$ & $V_{P S 37 D^{+}}$ \\
\hline 18 & rs56786794 & 11922278 & $\mathrm{~A}$ & 0.057 & $-22.95(-32.76--13.14)$ & $7.53 \times 10^{-6}$ & $M P P E 1^{\dagger}$ \\
\hline 13 & rs61971490 & 73064151 & $\mathrm{~T}$ & 0.045 & $-24.11(-34.45--13.77)$ & $8.10 \times 10^{-6}$ & \\
\hline 18 & rs12960421 & 11923803 & G & 0.058 & $-22.89(-32.72--13.06)$ & $8.23 \times 10^{-6}$ & $M P P E 1^{\dagger}$ \\
\hline 20 & rs4815993 & 7263756 & A & 0.348 & 10.09 (5.749-14.43) & $8.62 \times 10^{-6}$ & \\
\hline 4 & rs114558514 & 115943168 & $\mathrm{~T}$ & 0.108 & $16.51(9.389-23.63)$ & $8.99 \times 10^{-6}$ & $\mathrm{NDST}_{4}^{\dagger}$ \\
\hline 4 & rs74700222 & 115938513 & G & 0.108 & $16.51(9.389-23.63)$ & $8.99 \times 10^{-6}$ & NDST4 \\
\hline 4 & rs76144590 & 115936946 & G & 0.108 & $16.51(9.389-23.63)$ & $8.99 \times 10^{-6}$ & NDST4 \\
\hline 4 & rs77275720 & 115946034 & $\mathrm{C}$ & 0.108 & $16.54(9.395-23.68)$ & $9.26 \times 10^{-6}$ & NDST4 \\
\hline 6 & rs13201542 & 99934459 & A & 0.076 & $-17.47(-25.04--9.894)$ & $9.96 \times 10^{-6}$ & USP45 \\
\hline 6 & rs28385588 & 99915661 & G & 0.076 & $-17.47(-25.04--9.894)$ & $9.96 \times 10^{-6}$ & USP45 \\
\hline
\end{tabular}

CHR, chromosome; SNP, single-nucleotide polymorphism; BP, base pair position according to UCSC genome browser (NCBI37/hg19) and dbSNP build 150; A1, minor allele; MAF, minor allele frequency; CI, confidence interval. ${ }^{+}$Closer gene within 100 kilobases.

We analyzed if the best 150 ranked genes obtained in the gene-based association study (Supplementary Table S2) were significantly aggregated in specific categories of Gene Ontology for biological processes. Processes related with DNA packaging complex, DNA conformation change, chromosome organization and chromatin organization reached the established FDR $p$-value threshold (Table 3; Supplementary Figure S3). Nevertheless, the same genes (HIST2H2BE, HIST2H4B, SMC2, HIST2H3A, H2AFY, PRM2, PRM1, PRM3, $C D A N 1, T N P 2)$ were present in all these related biological processes.

Table 3. Enrichment analysis results obtained with the ShinyGO v0.61 application.

\begin{tabular}{|c|c|c|c|c|}
\hline Process Description & GO Term & $\begin{array}{c}\text { Number of Genes } \\
\text { in the Term }\end{array}$ & FDR $p$-Value & Overloaded Genes \\
\hline DNA packaging & GO:0006323 & 221 & $<0.001$ & $\begin{array}{c}\text { NCAPH, HIST2H2BE, HIST2H4B, SMC2, } \\
\text { HIST2H3A, H2AFY, PRM2, PRM1, } \\
\text { PRM3, CDAN1, TNP2 }\end{array}$ \\
\hline $\begin{array}{l}\text { DNA conformation } \\
\text { change }\end{array}$ & GO:0071103 & 325 & 0.001 & $\begin{array}{c}\text { NCAPH, HIST2H2BE, HIST2H4B, SMC2, } \\
\text { HIST2H3A, H2AFY, PRM2, PRM1, } \\
\text { PRM3, CDAN1, TNP2, RAD23B }\end{array}$ \\
\hline $\begin{array}{l}\text { Chromosome } \\
\text { organization }\end{array}$ & GO:0051276 & 1293 & 0.007 & $\begin{array}{c}\text { H2AFY, STAG1, NCAPH, MSL2, } \\
\text { HIST2H2AC, HIST2H2AB, HIST2H2BE, } \\
\text { HIST2H4B, HIST2H2AA4, RAD23B, } \\
\text { SMC2, RNF20, HIST2H3A, ATXN3, } \\
\text { RBL2, PRM2, SETD5, PPM1D, PRM1, } \\
\text { PRM3, CDAN1, TNP2 }\end{array}$ \\
\hline $\begin{array}{l}\text { Chromatin } \\
\text { organization }\end{array}$ & GO:0006325 & 849 & 0.039 & $\begin{array}{c}\text { H2AFY, MSL2, HIST2H2AC, } \\
\text { HIST2H2AB, HIST2H2BE, HIST2H4B, } \\
\text { HIST2H2AA4, RNF20, HIST2H3A, } \\
\text { ATXN3, RBL2, SETD5, PPM1D, } \\
\text { CDAN1, TNP2 }\end{array}$ \\
\hline
\end{tabular}




\section{Discussion}

In this work, we have reported possible genetic factors involved in the LS changes from the moment of starting anti-HCV therapy to SVR. In addition, our data suggest that processes related to DNA conformation are involved in these changes.

Although the statistically significant $p$-value threshold established for the GWAS was not reached by any SNP, some suggestive associations deserve attention. On one hand, and with respect to the top SNPs identified in our GWAS, the strongest signals were linked to the NDUF2 gene. It has been recently reported that the expression of Nduf2, a component of the complex I of the mitochondrial respiratory chain, was upregulated in the hepatic stellate cells (HSCs) from a rat model of alcohol-induced fibrosis. In this model, Nduf2 was involved in the regulation of fibrosis factors [24]. Other top SNPs were linked to MAN1A1 and AHRR locus. MAN1A1 is a mannosidase with an important role in the formation of mature glycoproteins, protein folding and in misfolded protein degradation in eukaryotes [25]. Overexpression of MAN1A1 in a transgenic zebrafish model promoted the development of steatosis, inflammation and hepatocellular carcinoma formation, and also induced the overexpression of MM9 [26], a metalloprotease that seems to be strongly involved in liver fibrosis resolution [27]. AHRR represses signal transduction promoted by the Aryl-hydrocarbon receptor (AhR) [28]. AhR, highly expressed in the liver, is a xenobiotic receptor that senses environmental toxicants and regulates xenobiotic metabolism [29]. Recently, a controversial but important role of this protein in liver fibrosis has been suggested. Specifically, knockout of AhR in HSCs causes spontaneous liver fibrosis; in contrast, a non-toxic AhR agonist exhibited in vivo anti-fibrotic activity in mice [30]. Therefore, a dysregulation on AHRR could interact with the role of AhR in a possible anti-fibrotic activity. On the other hand, and regarding the gene-based association study, we identified the LYPLAL1 gene as the top gene suggestively associated with the percentage of LS variations from baseline to SVR. Interestingly, a variant linked to this gene was related to histologic lobular inflammation/fibrosis in a GWAS performed on non-alcoholic fatty liver disease [31]. Due to all of these facts, future validations of these results in independent studies are warranted.

Among HCV-infected individuals with a more advanced liver disease, liver stiffness normalization, as a reflection of liver injury improvement after HCV-infection cure, might not be achieved. This non-return point in the course of liver disease would be more frequent among infected patients who carry genetic risk factors for fibrosis progression. Therefore, it could be hypothesized that genetic factors involved in liver disease progression during $\mathrm{HCV}$ active infection could also be associated with LS changes observed during the HCV treatment. Two GWAS were carried out among Caucasian individuals in the setting of $\mathrm{HCV}$ active infection [32,33], and several SNPs and their linked genes were related to this trait. However, none of them appeared in the top list of SNPs or genes associated with the endpoint analyzed herein, nor did they show associations at nominal $p$-value $(<0.05)$ (data not shown), suggesting that mechanisms involved in liver disease progression during $\mathrm{HCV}$ active infection are different to those involved in liver disease regression at SVR.

Interestingly, some of those top genes associated with the endpoint were grouped in linked GO categories related with the conformation of the DNA and chromatin. Recently, it has been reported that $\mathrm{HCV}$ infection induces genome-wide epigenetic changes through histone modifications that lead to changes in active and repressed chromatin and, consequently, reprograming of host gene expression. Besides, these changes persisted after $\mathrm{HCV}$ eradication with DAA-based treatment $[34,35]$. In addition, the persistence of this $\mathrm{HCV}$-induced expression signature was more common in patients with pre-treatment liver fibrosis and was related to the risk of HCC after HCV-infection cure [34,35]. In light of these findings, our enrichment analysis results suggest the existence of a genetic susceptibility for such epigenetic modifications induced by the HCV infection.

In spite of LS at SVR being a strong predictor of liver disease outcome in HCVinfected patients with pre-treatment advanced fibrosis [14,15], other factors have been independently associated with liver events' occurrence. For instance, HIV-infection and 
non-genotype 3-HCV-infection have been related to a lower risk of HCC [36], whereas the anti-HCV therapy used as well as the presence of diabetes have been associated with incremented risk of HCC [37]. Therefore, it will be necessary to explore if the genetic factors described herein have a role in the occurrence of these events as well as to determine their real effect, taking into account all those non-genetic factors.

This work has some limitations. Firstly, because the collection of samples was not mandatory to enter patients in the GEHEP-011 cohort, a relatively low number of individuals were included in our study. This fact, together with the possible polygenetic nature of the LS changes from baseline to SVR, would explain why no SNP reached the $p$-value threshold established for GWAS. However, the biological plausibility of some of the genes linked to those SNPs reported as suggestively associated with the main endpoint and, the concordance of the enrichment analysis results with the molecular mechanisms proposed for the persistence of the risk for liver events' development in HCV-cured individuals, are strengths of this work. Second, unfortunately, we could not include a replication sample. Therefore, replication of the findings in other cohorts is needed to confirm these findings. Additionally, if our results are replicated, it would be necessary to identify whether the effect size of the genetic signals reported herein are homogeneous in the population subgroups stratified according to HIV-infection or treatment received. It is important to note that we have not taken into account the duration of treatment and, therefore, we do not know if this issue could be affecting our results. However, all LS determinations at SVR were performed 12 weeks after the end of anti-HCV therapy. Moreover, it is known that the use of IFN could affect the regression of the LS after HCV-infection cure. Although a low proportion of patients were treated with DAAs combined with pegylated interferon, our results were corrected by this factor. Finally, the inclusion of HCV-infected individuals was conditioned by the availability of blood samples. Therefore, a selection bias cannot be excluded. In fact, our study population was younger than that of the entire cohort. Moreover, our study population had a higher proportion of HIV-infected subjects, and a higher proportion of subjects who received DAAs combined with pegylated interferon than that observed in the entire cohort. Nevertheless, our results were corrected by all of these factors.

In conclusion, we have performed the first GWAS on LS values' changes from baseline to SVR among HCV-infected patients, HIV-coinfected or not, with pre-treatment advanced liver fibrosis. Our results suggest that these changes in LS values could be partially conditioned by multiple gene variants. Although further studies will be necessary to confirm our results, our work provides clues about the possible molecular pathways involved in this condition.

Supplementary Materials: The following are available online at https:/ /www.mdpi.com/article/10 .3390/diagnostics11081501/s1, Figure S1: Scatterplot of the two main eigenvectors obtained from the principal component analysis performed on different ethnicities, including the GWAS population. Red lines: mean PC vectors. Blue lines: mean PC vectors \pm 6SD. Figure S2: Quantile-Quantile (Q-Q) plot of the observed and expected $\chi 2$ values obtained from the GWAS. Figure S3: Relationship between enriched pathways obtained with top 150 genes from Magma using the ShinyGO v0.61. Nodes appear connected if they share $20 \%$ or more genes. Thicker edges represent more overlapped genes. Darker nodes are more significantly enriched gene sets. Bigger nodes represent larger gene sets. Table S1: Direct-acting antiviral regimens used in the study population for achieving sustained viral response $(n=242)$. Table S2: Top 150 genes associated with the percentage of LS changes at the SVR time point with respect to the LS value measured at the moment of therapy starting according to MAGMA gene-wise statistics.

Author Contributions: Conceptualization, L.M.R., J.M. and J.A.P.; Methodology, L.M.R., M.E.S., A.R. (Antonio Rivero) and A.R.-J.; Formal Analysis, L.M.R., M.E.S., I.d.R. and A.R. (Agustín Ruiz); Data Curation, L.M.R., M.E.S., A.C.-G., A.R.-J., I.d.1.S., S.R.-B., L.M., D.M., R.P., C.G., M.F.-F. and A.G.-S.; Writing-Original Draft Preparation, L.M.R., A.C.-G., M.E.S., J.M. and J.A.P.; Writing-Review and Editing, All authors; Visualization, L.M.R., M.E.S., A.R. (Agustín Ruiz) and A.C.-G.; Supervision, L.M.R. All authors have read and agreed to the published version of the manuscript. 
Funding: This work was supported by a grant from the Consejería de Salud de la Junta de Andalucía (project PI-0001/2017), and partially founded by the Instituto de Salud Carlos III (Projects PI16/01443 and PI19/01312), integrated in the national I+D+i 2013-2016, 2016-2019, and co-funded by the European Union (ERDF/ESF, "Investing in your future"), by the Spanish Network for AIDS investigation (RIS) (www.red.es/redes/inicio (accessed on 1 January 2021)) (RD16/0025/0040), as a part of the Nacional I+ D+I, ISCIII Subdirección General de Evaluación and the European Fund for Development of Regions (FEDER) and by GEHEP-SEIMC (GEHEP-011 project). J.A.P. has received a research extension grant from the Programa de Intensificación de la Actividad de Investigación del Servicio Nacional de Salud Carlos III (I3SNS). A.C.-G. has received a Río Hortega grant from the Instituto de Salud Carlos III (grant number CM19/00251). A.G.-S. is the recipient of a Miguel Servet Research Contract by Instituto de Salud Carlos III (CP18/00146). I.R. is the recipient of a P-FIS Research Contract by Instituto de Salud Carlos IIII (FI20/00215). A.Ruiz. is supported by national grants PI13/02434, PI16/01861 and PI19/01301. Acción Estratégica en Salud is integrated into the Spanish National R + D + I Plan and funded by ISCIII (Instituto de Salud Carlos III), Subdirección General de Evaluación and the Fondo Europeo de Desarrollo Regional (FEDER "Una manera de Hacer Europa") and received support from the European Union/EFPIA Innovative Medicines Initiative Joint Undertaking ADAPTED and MOPEAD projects (Grants No. 115975 and 115985) and PREADAPT project (JPco-fuND-2. Grant number AC19/00097).

Institutional Review Board Statement: This study was conducted according to the guidelines of the Declaration of Helsinki, and approved by the Ethics Committee of the Hospital Universitario de Valme (Ref: 1612-N-17).

Informed Consent Statement: Informed consent was obtained from all subjects involved in the study.

Data Availability Statement: The data presented in this study are available on request from the corresponding author and the Ethics Committee of the Hospital Universitario de Valme. The data are not publicly available due to the conditions established in the Spanish Law for Biomedical Research (Ley 14/2007, de 3 de julio).

Conflicts of Interest: The authors declare no conflict of interest.

\section{References}

1. Backus, L.I.; Belperio, P.S.; Shahoumian, T.A.; Mole, L.A. Direct-acting antiviral sustained virologic response: Impact on mortality in patients without advanced liver disease. Hepatology 2018, 68, 827-838. [CrossRef]

2. Carrat, F.; Fontaine, H.; Dorival, C.; Simony, M.; Diallo, A.; Hezode, C.; De Ledinghen, V.; Larrey, D.; Haour, G.; Bronowicki, J.P.; et al. Clinical outcomes in patients with chronic hepatitis $\mathrm{C}$ after direct-acting antiviral treatment: A prospective cohort study. Lancet 2019, 393, 1453-1464. [CrossRef]

3. Merchante, N.; Rivero-Juarez, A.; Tellez, F.; Merino, D.; Rios-Villegas, M.J.; Villalobos, M.; Omar, M.; Rincon, P.; Rivero, A.; Perez-Perez, M.; et al. Sustained virological response to direct-acting antiviral regimens reduces the risk of hepatocellular carcinoma in HIV/HCV-coinfected patients with cirrhosis. J. Antimicrob. Chemother. 2018, 73, 2435-2443. [CrossRef]

4. Nahon, P.; Bourcier, V.; Layese, R.; Audureau, E.; Cagnot, C.; Marcellin, P.; Guyader, D.; Fontaine, H.; Larrey, D.; De Ledinghen, V.; et al. Eradication of Hepatitis C Virus Infection in Patients With Cirrhosis Reduces Risk of Liver and Non-Liver Complications. Gastroenterology 2017, 152, 142-156.e2. [CrossRef] [PubMed]

5. Kanwal, F.; Kramer, J.R.; Asch, S.M.; Cao, Y.; Li, L.; El-Serag, H.B. Long-Term Risk of Hepatocellular Carcinoma in HCV Patients Treated With Direct Acting Antiviral Agents. Hepatology 2020, 71, 44-55. [CrossRef] [PubMed]

6. $\quad$ van der Meer, A.J.; Feld, J.J.; Hofer, H.; Almasio, P.L.; Calvaruso, V.; Fernandez-Rodriguez, C.M.; Aleman, S.; Ganne-Carrie, N.; D'Ambrosio, R.; Pol, S.; et al. Risk of cirrhosis-related complications in patients with advanced fibrosis following hepatitis $\mathrm{C}$ virus eradication. J. Hepatol. 2017, 66, 485-493. [CrossRef] [PubMed]

7. Marrero, J.A.; Kulik, L.M.; Sirlin, C.B.; Zhu, A.X.; Finn, R.S.; Abecassis, M.M.; Roberts, L.R.; Heimbach, J.K. Diagnosis, Staging, and Management of Hepatocellular Carcinoma: 2018 Practice Guidance by the American Association for the Study of Liver Diseases. Hepatology 2018, 68, 723-750. [CrossRef]

8. Pawlotsky, J.; Negro, F.; Aghemo, A.; Berenguer, M.O.; Dalgard, M.; Dusheiko, G.; Marra, F.; Puoti, M.; Wedemeyer, H. EASL recommendations on treatment of hepatitis C: Final update of the series. J. Hepatol. 2020, 73, 1170-1218. [CrossRef]

9. Bloom, S.; Kemp, W.; Nicoll, A.; Roberts, S.K.; Gow, P.; Dev, A.; Bell, S.; Sood, S.; Kronborg, I.; Knight, V.; et al. Liver stiffness measurement in the primary care setting detects high rates of advanced fibrosis and predicts liver-related events in hepatitis C. J. Hepatol. 2018, 69, 575-583. [CrossRef]

10. Macias, J.; Marquez, M.; Tellez, F.; Merino, D.; Jimenez-Aguilar, P.; Lopez-Cortes, L.F.; Ortega, E.; von Wichmann, M.A.; Rivero, A.; Mancebo, M.; et al. Risk of liver decompensation among HIV/hepatitis C virus-coinfected individuals with advanced fibrosis: Implications for the timing of therapy. Clin. Infect. Dis. 2013, 57, 1401-1408. [CrossRef] 
11. Merchante, N.; Rivero-Juarez, A.; Tellez, F.; Merino, D.; Jose Rios-Villegas, M.; Marquez-Solero, M.; Omar, M.; Macias, J.; Camacho, A.; Perez-Perez, M.; et al. Liver stiffness predicts clinical outcome in human immunodeficiency virus/hepatitis $C$ virus-coinfected patients with compensated liver cirrhosis. Hepatology 2012, 56, 228-238. [CrossRef] [PubMed]

12. Lledo, G.M.; Carrasco, I.; Benitez-Gutierrez, L.M.; Arias, A.; Royuela, A.; Requena, S.; Cuervas-Mons, V.; de Mendoza, C. Regression of liver fibrosis after curing chronic hepatitis $C$ with oral antivirals in patients with and without HIV coinfection. Aids 2018, 32, 2347-2352. [CrossRef] [PubMed]

13. Malin, J.J.; Boesecke, C.; Schwarze-Zander, C.; Wasmuth, J.C.; Schlabe, S.; Trebicka, J.; Spengler, U.; Llibre, J.M.; Jou, T.; Vasylyev, M.; et al. Liver stiffness regression after successful Hepatitis C treatment is independent of HIV coinfection. HIV Med. 2019, 20, 230-236. [CrossRef] [PubMed]

14. Corma-Gomez, A.; Macias, J.; Tellez, F.; Freyre-Carrillo, C.; Morano, L.; Rivero-Juarez, A.; Rios, M.J.; Alados, J.C.; Vera-Mendez, F.J.; Merchante, N.; et al. Liver Stiffness at the Time of Sustained Virological Response Predicts the Clinical Outcome in People Living With Human Immunodeficiency Virus and Hepatitis C Virus With Advanced Fibrosis Treated With Direct-acting Antivirals. Clin. Infect. Dis. 2020, 71, 2354-2362. [CrossRef]

15. Corma-Gomez, A.; Morano, L.; Tellez, F.; Rivero-Juarez, A.; Real, L.M.; Alados, J.C.; Rios-Villegas, M.J.; Vera-Mendez, F.J.; Munoz, R.P.; Geijo, P.; et al. HIV infection does not increase the risk of liver complications in hepatitis $C$ virus-infected patient with advanced fibrosis, after sustained virological response with direct-acting antivirals. Aids 2019, 33, 1167-1174. [CrossRef]

16. Castera, L.; Forns, X.; Alberti, A. Non-invasive evaluation of liver fibrosis using transient elastography. J. Hepatol. 2008, 48, 835-847. [CrossRef]

17. Real, L.M.; Fernandez-Fuertes, M.; Saez, M.E.; Rivero-Juarez, A.; Frias, M.; Tellez, F.; Santos, J.; Merino, D.; Moreno-Grau, S.; Gomez-Salgado, J.; et al. A genome-wide association study on low susceptibility to hepatitis C virus infection (GEHEP012 study). Liver Int. 2019, 39, 1918-1926. [CrossRef]

18. Barsh, G.S.; Copenhaver, G.P.; Gibson, G.; Williams, S.M. Guidelines for genome-wide association studies. PLoS Genet. 2012, 8, e1002812. [CrossRef]

19. McLaren, W.; Gil, L.; Hunt, S.E.; Riat, H.S.; Ritchie, G.R.; Thormann, A.; Flicek, P.; Cunningham, F. The Ensembl Variant Effect Predictor. Genome Biol. 2016, 17, 122. [CrossRef]

20. de Leeuw, C.A.; Mooij, J.M.; Heskes, T.; Posthuma, D. MAGMA: Generalized gene-set analysis of GWAS data. PLoS Comput. Biol. 2015, 11. [CrossRef] [PubMed]

21. Ge, S.X.; Jung, D.; Yao, R. ShinyGO: A graphical gene-set enrichment tool for animals and plants. Bioinformatics 2020, 36, 2628-2629. [CrossRef]

22. Ashburner, M.; Ball, C.A.; Blake, J.A.; Botstein, D.; Butler, H.; Cherry, J.M.; Davis, A.P.; Dolinski, K.; Dwight, S.S.; Eppig, J.T.; et al. Gene ontology: Tool for the unification of biology. The Gene Ontology Consortium. Nat. Genet. 2000, 25, 25-29. [CrossRef]

23. Consortium, G.O. The Gene Ontology resource: Enriching a GOld mine. Nucleic Acids Res. 2021, 49, D325-D334. [CrossRef]

24. Yin, L.; Zhang, Y.; Shi, H.; Feng, Y.; Zhang, Z.; Zhang, L. Proteomic profiling of hepatic stellate cells in alcohol liver fibrosis reveals proteins involved in collagen production. Alcohol 2020, 86, 81-91. [CrossRef] [PubMed]

25. Pan, S.; Cheng, X.; Sifers, R.N. Golgi-situated endoplasmic reticulum alpha-1, 2-mannosidase contributes to the retrieval of ERAD substrates through a direct interaction with gamma-COP. Mol. Biol. Cell 2013, 24, 1111-1121. [CrossRef] [PubMed]

26. Tu, H.C.; Hsiao, Y.C.; Yang, W.Y.; Tsai, S.L.; Lin, H.K.; Liao, C.Y.; Lu, J.W.; Chou, Y.T.; Wang, H.D.; Yuh, C.H. Up-regulation of golgi alpha-mannosidase IA and down-regulation of golgi alpha-mannosidase IC activates unfolded protein response during hepatocarcinogenesis. Hepatol. Commun. 2017, 1, 230-247. [CrossRef] [PubMed]

27. Feng, M.; Ding, J.; Wang, M.; Zhang, J.; Zhu, X.; Guan, W. Kupffer-derived matrix metalloproteinase-9 contributes to liver fibrosis resolution. Int. J. Biol. Sci. 2018, 14, 1033-1040. [CrossRef] [PubMed]

28. Evans, B.R.; Karchner, S.I.; Allan, L.L.; Pollenz, R.S.; Tanguay, R.L.; Jenny, M.J.; Sherr, D.H.; Hahn, M.E. Repression of aryl hydrocarbon receptor (AHR) signaling by AHR repressor: Role of DNA binding and competition for AHR nuclear translocator. Mol. Pharm. 2008, 73, 387-398. [CrossRef]

29. Beischlag, T.V.; Luis Morales, J.; Hollingshead, B.D.; Perdew, G.H. The aryl hydrocarbon receptor complex and the control of gene expression. Crit. Rev. Eukaryot. Gene Expr. 2008, 18, 207-250. [CrossRef] [PubMed]

30. Yan, J.; Tung, H.C.; Li, S.; Niu, Y.; Garbacz, W.G.; Lu, P.; Bi, Y.; Li, Y.; He, J.; Xu, M.; et al. Aryl Hydrocarbon Receptor Signaling Prevents Activation of Hepatic Stellate Cells and Liver Fibrogenesis in Mice. Gastroenterology 2019, 157, 793-806.e14. [CrossRef]

31. Speliotes, E.K.; Yerges-Armstrong, L.M.; Wu, J.; Hernaez, R.; Kim, L.J.; Palmer, C.D.; Gudnason, V.; Eiriksdottir, G.; Garcia, M.E.; Launer, L.J.; et al. Genome-wide association analysis identifies variants associated with nonalcoholic fatty liver disease that have distinct effects on metabolic traits. PLoS Genet. 2011, 7. [CrossRef] [PubMed]

32. Patin, E.; Kutalik, Z.; Guergnon, J.; Bibert, S.; Nalpas, B.; Jouanguy, E.; Munteanu, M.; Bousquet, L.; Argiro, L.; Halfon, P.; et al. Genome-wide association study identifies variants associated with progression of liver fibrosis from HCV infection. Gastroenterology 2012, 143, 1244-1252.e12. [CrossRef] [PubMed]

33. Ulveling, D.; Le Clerc, S.; Cobat, A.; Labib, T.; Noirel, J.; Laville, V.; Coulonges, C.; Carpentier, W.; Nalpas, B.; Heim, M.H.; et al. A new 3 p25 locus is associated with liver fibrosis progression in human immunodeficiency virus/hepatitis $C$ virus-coinfected patients. Hepatology 2016, 64, 1462-1472. [CrossRef] [PubMed] 
34. Hamdane, N.; Juhling, F.; Crouchet, E.; El Saghire, H.; Thumann, C.; Oudot, M.A.; Bandiera, S.; Saviano, A.; Ponsolles, C.; Roca Suarez, A.A.; et al. HCV-Induced Epigenetic Changes Associated with Liver Cancer Risk Persist After Sustained Virologic Response. Gastroenterology 2019, 156, 2313-2329.e7. [CrossRef] [PubMed]

35. Perez, S.; Kaspi, A.; Domovitz, T.; Davidovich, A.; Lavi-Itzkovitz, A.; Meirson, T.; Alison Holmes, J.; Dai, C.Y.; Huang, C.F.; Chung, R.T.; et al. Hepatitis C virus leaves an epigenetic signature post cure of infection by direct-acting antivirals. PLoS Genet. 2019, 15, e1008181. [CrossRef]

36. Corma-Gómez, A.; Macías, J.; Lacalle-Remigio, J.R.; Téllez, F.; Morano, L.; Rivero, A.; Serrano, M.; Ríos, M.J.; Vera-Méndez, F.J.; Alados, J.C.; et al. HIV infection is associated with lower risk of hepatocellular carcinoma after sustained virological response to direct-acting antivirals in hepatitis $C$ infected-patients with advanced fibrosis. Clin. Infect. Dis. 2020, in press. [CrossRef]

37. Rinaldi, L.; Perrella, A.; Guarino, M.; De Luca, M.; Piai, G.; Coppola, N.; Pafundi, P.C.; Ciardiello, F.; Fasano, M.; Martinelli, E.; et al. Incidence and risk factors of early HCC occurrence in $\mathrm{HCV}$ patients treated with direct acting antivirals: A prospective multicentre study. J. Transl. Med. 2019, 17, 292-301. [CrossRef] 